\title{
Essential fatty acids and Barratt impulsivity in gambling disorder
}

Patricia Sanchez-Paez ${ }^{1 *}$ (D), Josefa Perez-Templado ${ }^{1}$, Jeronimo Saiz-Ruiz ${ }^{1,2,3,4}$, Oscar Pastor ${ }^{3,5,6}$ and Angela Ibañez ${ }^{1,2,3,4}$

\begin{abstract}
Background: Polyunsaturated fatty acids (PUFA) have been long implicated in the etiopathogenesis of mental illnesses, including disorders characterized by high impulsivity. The objective of most of the studies in this field is to determine the effect of omega-3 supplementation on the impulsive symptoms. In contrast, studies analyzing basal PUFA composition in patients with impulsive behaviors are very scarce, results are not yet conclusive, and to date, no publication has specifically evaluated this in gambling disorder. Therefore, the main purpose of this research is to examine the relationship between basal PUFA composition of plasma and erythrocyte membrane and impulsivity in subjects with gambling disorder.

Methods: It is an observational and cross-sectional study. The sample consisted of fifty-five men with gambling disorder, who voluntarily accepted to participate. Basal composition of PUFA in plasma and erythrocyte membrane was assessed by gas chromatography and mass spectrometry. Trait impulsivity was measured by the Barratt Impulsiveness Scale version 11 (BIS-11).

Results: Arachidonic acid (AA)/eicosapentaenoic acid (EPA) ratio in the erythrocyte membrane was negatively correlated with total scores in BIS-11. It was also observed that impulsive gamblers had a higher proportion of EPA and a lower value of AA/EPA and AA/docosahexaenoic acid (DHA) ratio in erythrocyte membrane than non-impulsive gamblers.

Conclusions: These results support the hypothesis that alteration of basal PUFA composition exists in disorders characterized by high impulsivity, although the direction of this is still unknown. Unfortunately, the empirical literature on this field is non-existent at the time and we have no direct means to support or refute these outcomes. Further research is needed to determine the relationship between essential fatty acids and disorders characterized by high impulsivity.
\end{abstract}

Keywords: Gambling disorder, Impulsivity, Barratt, Essential fatty acids, Polyunsaturated fatty acids, Omega-3, Omega-6

\section{Background}

The omega-3 (n-3) and omega-6 (n-6) are essential polyunsaturated fatty acids (PUFA). Humans cannot synthesize them, whereby they must be obtained from the diet or from supplements. Technically, we only need to obtain from dietary resources: alpha-linolenic acid (ALA) of the omega-3 family, to synthesize longer chain $n-3$, and linoleic acid (LA) of the omega- 6 family, to synthesize longer chain $n-6$. However, studies have shown that humans are inefficient at

\footnotetext{
* Correspondence: patripaez66@hotmail.com

'Department of Psychiatry, Hospital Universitario Ramon y Cajal, Madrid, Spain

Full list of author information is available at the end of the article
}

converting short to long chain fatty acids and thus, the tissue composition of all n-3 and n-6 lipids partially reflects dietary consumption [1]. The main omega-3 derived from ALA are docosahexaenoic acid (DHA) and eicosapentaenoic acid (EPA), which also may be obtained from seafood and plant sources. The main omega- 6 derived from LA is arachidonic acid (AA), which depends mainly on the intake of vegetable oils [2].

The role of essential fatty acids (EFA) in brain functioning is currently unknown. However, they are a major structural component of neuronal membranes, and changing the fatty acid composition of neuronal membranes, leads to functional changes in the activity of

(c) The Author(s). 2020 Open Access This article is distributed under the terms of the Creative Commons Attribution 4.0 International License (http://creativecommons.org/licenses/by/4.0/), which permits unrestricted use, distribution, and reproduction in any medium, provided you give appropriate credit to the original author(s) and the source, provide a link to the Creative Commons license, and indicate if changes were made. The Creative Commons Public Domain Dedication waiver (http://creativecommons.org/publicdomain/zero/1.0/) applies to the data made available in this article, unless otherwise stated. 
receptors and other proteins embedded in the membrane phospholipid $[3,4]$. They also regulate gene expression involved in neurotransmission and synaptic plasticity [5] and have a role in the inflammatory and cellular signaling through the complex eicosanoid pathway [6].

In addition, it is needed a balance in $n-6 / n-3$ ratio, to maintain an adequate functioning of the organism. However, the value of this ratio is higher than it should be, due to the western diet modification in favor of the increase of omega-6 [7].

The study of essential fatty acids in Psychiatry is interesting because changes in the diet would alter the n-3 and n- 6 composition of the neuronal membranes, affecting multiple cellulars and molecular processes involved in the cerebral function and neurotransmission systems associated with pathology. This implies that adequate dietary quantities of PUFA could be a natural, cheap and non-invasive treatment with no adverse effects for the maintenance of mental health $[8,9]$.

All this biological basis, together with current scientific evidence, supports a possible relationship between EFA and mental disorders, including disorders characterized by high impulsivity, such as attention deficit hyperactivity disorder (ADHD), personality disorders [10], substance use disorders (SUD), suicidal behavior or aggression [11]. Thus, there has been a growing interest in the study of omega- 3 in recent years. Most of them have been performed in patients with ADHD, with several meta-analyses recently published. Most have been carried out with the aim of examining the effect of omega-3 supplementation on the symptoms of ADHD [12]. The results obtained in some of them show that omega-3 supplementation could have a small, but beneficial effect on the symptoms of the ADHD, being the EPA the one that seems to reduce more the symptoms $[13,14]$. However, there are also some meta-analyses that found no statistically significant benefit [12]. The literature review indicates that small size of the estimated effect of omega-3 supplementation does not provide enough evidence to recommend n-3 as an alternative treatment, although, its use as a supplement along with other treatments is justified because of its favorable side effects profile and the results described. However, despite these promising findings, recent review points to the methodological weaknesses of all clinical trials on which these meta-analyses are based [15]. Issues that might challenge an adequate double-blind placebocontrolled design are various, suggesting to the need for omega-3 clinical trials to adhere to the rigorous standards required of pharmaceutical clinical trials [12].

In contrast, studies analyzing basal PUFA composition in patients with impulsive behaviors are very scarce and results are not yet conclusive. The first meta-analyses that analyzed omega-3 composition in ADHD children find a lower proportion of EPA and DHA in these patients [12]. Controlled trials have also shown an association between suicide attempts and a lower proportion of EPA or DHA in plasma and red blood cells [12]. Likewise, low plasma levels of DHA and high dihomogammalinolenic acid (DGLA) were found in individuals with alcohol abuse and violent behaviors [12]. A recent study finds a negative association between DHA levels and aggression, and a positive association between the ratio AA/DHA and aggression in patients from a forensic psychiatry unit [16].

Nowadays, scientific evidence in animal studies suggests that PUFAs could play a role in the abuse of substances through their action on central serotonergic and dopaminergic systems involved in the reward system [17]. However, studies that directly evaluate the role of EFAs in this type of pathology are scarce and focus on alcohol and cocaine abuse. In the review of this topic by Borsonelo and Galduroz (2008), is concluded the benefit of taking PUFAs as an adjuvant treatment in the alcohol and cocaine use disorders, because of their a role in membrane permeability which could stabilize and repair the damage caused by continued substance use or poor dietary habits of these patients [12]. On the other hand, two studies conducted on patients with cocaine and alcohol dependence reported an association between low levels of omega- 3 and high aggressive conduct and this low PUFA status at baseline was a better predictor of relapse than cocaine use, sociodemographic or clinical parameters [12]. These results suggest, but do not prove, the existence of a causal relationship between PUFA status and the vulnerability to the development of addictive disorders, and provide a rationale for the exploration of possible relationships between relapse to addictive disorders and PUFA status in observational and interventional trials.

Few studies have examined a possible relationship between PUFAs and BIS-11 scores, but to date, no publication has specifically evaluated this in gambling disorder [18-20]. The scarce studies in this field, which evaluate a possible effect of fatty acid supplementation on BIS-11 scores, show no enlightening results $[21,22]$. In addition, these have numerous methodological limitations.

Reviewing the possible association between basal PUFA composition and scores on the BIS-11, we only found published studies evaluating PUFA in plasma, and none of which evaluates the erythrocyte membrane composition [18-20]. This is striking, considering this method (the composition of PUFA in erythrocyte membrane) is better than the plasma concentration or composition, to provide in clinical practice, a reliable estimate of the basal PUFA values [12], and precisely, this is one of the strengths of the present study. 
The main aim of this study is to explore the relationship between PUFA composition of plasma and erythrocyte membrane and impulsivity in subjects with gambling disorder. Our hypothesis is to find a different composition of PUFA among pathological gamblers depending on its impulsivity.

\section{Methods}

\section{Participants}

It is an observational and cross-sectional study. Participants were fifty-five men diagnosed with gambling disorder, who voluntarily attended to the Gambling Addiction Unit of Ramón y Cajal University Hospital to receive counseling and treatment between May 2010 and June 2011.

The inclusion criteria were:

- Caucasian men. The reason for excluded women in the study is because of the high prevalence of gambling disorder among men and the possible differences in both the PUFA and clinical profile of gambling between women and men. So despite being a limitation, it would allow obtaining a more homogeneous sample.

- Over 18 years.

- Diagnoses of pathological gambling per DSM-IV-TR criteria (APA, 2000).

The exclusion criteria were:

- Diagnosis of schizophrenia, bipolar disorder, mental retardation or organic mental disorder.

- Dyslipidemia or current treatment with lipidlowering drugs.

All subjects give voluntary written informed consent to participate in research under the ethics, consent, and permissions of Comité de Ética de la Investigación (CEIC) del Hospital Universitario Ramón y Cajal. The research project was approved by this ethics committee.

Subjects did not receive any incentives for their participation.

\section{Instruments}

\section{Medical history}

It was collected using a protocolized medical history interview about socio-demographic variables, personal and family history and clinic and history of gambling.

\section{Comorbidity}

All participants were assessed for comorbidity using the Structured Clinical Interview for DSM-IV-TR Axis I Disorders (SCID I), [23].

\section{Dietary habits}

Dietary habits were assessed retrospectively by asking about the intake frequency per week of foods rich in EFA (seafood and nuts) during the last year.

Body mass index (BMI) and smoking status were determined.

\section{Diagnostic and statistical manual of mental disorders (DSM-IV)}

It is a self-report scale used for the diagnosis of pathological gambling, based on DSM-IV criteria and validated to Spanish. The answer format is yes or no. Scores ranging from 0 to 10 and a value of 5 or more are considered indicative of pathological gambling according to DSM-IV $[24,25]$.

\section{Barratt impulsiveness scale version 11 (BIS-11)}

Impulsivity was assessed by this scale. The eleventh revision of BIS-11 [26] is one of the most widely used instruments in impulsivity scientific literature [27]. In this study, we use Spanish validation [28]. It is a thirty question self-report scale that is designed to assess various domains of impulsivity, including attentional impulsivity (ability the sustain attention on a given task), motor impulsivity (ability to control behavioral activity), and nonplanning impulsivity (associated with the tendency to think about behaviors and plans before acting). The total score ranges between 30 and 120 and is the result of the sum of three different subscales [29]. It uses a four-point Likert scale from "Rarely/Never" [1] to "Almost Always/ Always" [4], where 4 indicates the most impulsive response [12]. A common question asked concerning the BIS-11 is what score can be used to designate an individual as highly impulsive. Several previous studies have used a BIS-11 total score of 74 to designate high impulsiveness [26]. However, current data suggest that a total score of 72 or above should be used to classify an individual as highly impulsive. Thus, Stanford proposes these instrument cut-off points [27]:

- Highly impulsive (higher than or equal to 72).

- Normality (between 52 and 71)

- Low impulsive (lower than or equal to 51).

In the present research, subjects were also categorized into high and low impulsivity, using the same method as Stanford study.

\section{PUFA analyses}

Fasting blood test was collected under standardized conditions in a 10-mL tube containing EDTA-K3 anticoagulant. Composition of PUFA was analyzed by Biochemistry laboratory by gas chromatography and mass spectrometric detection procedure. 
Red blood cells were separated from plasma by lowspeed centrifugation. Plasma and packed red cells were stored in cryotubes at $-80^{\circ} \mathrm{C}$ until they were analyzed using the direct transesterification procedure according to Lepage and Roy [30]. Samples were analyzed by flame-ionization gas chromatography (HP-INNOWAX) using a $30 \mathrm{~m}, 0.25 \mathrm{M}, 0.1 \mathrm{~mm}$ internal diameter capillary column. One microliter of the sample was auto-injected into the column, and individual fatty acids were quantified. Fatty acid peaks were identified by comparison with known fatty acid standards and quantitated by comparison to the internal standard (GLC-462, NuCheck-INC).

\section{Statistic analysis}

Qualitative data were reported as absolute frequencies and percentages and quantitative data as mean, standard deviation (SD), median, minimum and maximum. Comparison of quantitative variables between groups was performed using the U-Mann Whitney test. Qualitative data were compared using the Chi-square or Fisher's exact test depending on the distribution. Multiple comparisons between groups were performed by correcting the $p$-value by the Bonferroni method. Correlation between quantitative variables was studied with the Rho Spearman coefficient. All statistical tests were considered bilateral and as significant $p$-values, those less than 0.05 . Data were analyzed with the statistical program SPSS 20.0.

\section{Results}

\section{Sociodemographic characteristics}

Sociodemographic characteristics of the sample are described in Table 1.

\section{Clinical characteristics}

Clinical characteristics of the sample are shown in Table 2.

\section{Comorbidity with substance use disorders}

Comorbidity of pathological gambling and substance use disorders (SUD) are shown in Table 3.

\section{Barratt impulsiveness scale (BIS-11)}

The mean of the total score on the BIS-11 was 70.96, with a standard deviation of 10.872 and a median of 71 . The minimum value was 50 and the maximum 103. The categorized results from low to high impulsive according to the total scores on the BIS-11 are shown in Table 4.

The scores in each of the subscales were:

- Attention impulsivity: mean was 18.5 , standard deviation 2.989 and median 18.5. The minimum value was 11 and the maximum 26 .
Table 1 Demographic characteristics

\begin{tabular}{ll}
\hline Demographic variables & $\mathrm{n}(\%)$ \\
\hline Age & $7(12.7)$ \\
18-29 years & $25(45.5)$ \\
30-44 years & $21(38.2)$ \\
$45-64$ years & $2(3.6)$ \\
$\geqq 65$ & \\
Marital status & $20(36.4)$ \\
Single & $25(45.5)$ \\
Married & $7(12.7)$ \\
Divorced or separated & $3(5.4)$ \\
Widowed & \\
Educational level & $19(34.5)$ \\
Primary education or less & $25(44.7)$ \\
Secondary studies & $11(20.8)$ \\
University studies & \\
Occupational status & $2(3.6)$ \\
Student & $37(67.3)$ \\
Employed & $11(20)$ \\
Unemployed & $5(9.1)$ \\
Retired &
\end{tabular}

- Motor impulsivity: mean was 22.61, standard deviation 5.101 and median 21. The minimum value was 13 and the maximum 36.

- Non-planning impulsivity: mean was 29.94, standard deviation 5.564 and median 29. The minimum value was 20 and the maximum 46.

Table 2 Clinical characteristics

\begin{tabular}{ll}
\hline Clinical variables & $\mathrm{m}(\mathrm{P} 50)^{\mathrm{a}} / \mathrm{n}(\%)^{\mathrm{b}}$ \\
\hline Type of gambling & \\
Slot Machines & $46(83.6)^{\mathrm{a}}$ \\
Poker & $1(1.8)^{\mathrm{a}}$ \\
Lottery & $4(7.3)^{\mathrm{a}}$ \\
Casino & $4(7.3)^{\mathrm{a}}$ \\
Last time gambling & \\
$>60$ days & $22(44)^{\mathrm{a}}$ \\
30-60 days & $9(18)^{\mathrm{a}}$ \\
15-30 days & $7(14)^{\mathrm{a}}$ \\
Frequency of gambling & \\
5-7 days a week & $32(58.2)^{\mathrm{a}}$ \\
3-4 days a week & $6(10.9)^{\mathrm{a}}$ \\
1-2 days a week & $9(16.4)^{\mathrm{a}}$ \\
Hours a day spent gambling & \\
Hours a day & $5.57(5)^{\mathrm{b}}$ \\
\hline
\end{tabular}


Table 3 Comorbidity with substance use disorders (SUD)

\begin{tabular}{lll}
\hline Comorbidity with substance use disorders (SUD) & \\
\hline Alcohol & $\mathrm{n}$ & $\%$ \\
Cannabis & 21 & 38.2 \\
Cocaine & 14 & 25.5 \\
Other & 12 & 21.8 \\
& 3 & 5.5
\end{tabular}

The subscales were also categorized into high and low impulsivity, using the same method as in a recent study [31], which established as the cut-off the mean scores of the sample in each of the subscales. They justified not considering the confidence intervals around the mean, corresponding to moderate scores, because of the small sample size.

\section{Analysis of PUFA and impulsivity}

In this study, the possible relationship between essential fatty acids (percent composition in plasma and erythrocyte membrane and plasma concentration) and the impulsivity assessed by BIS-11 were analyzed in the sample of pathological gamblers. There were no statistically significant differences $(p<0.05)$ in age, BMI, fish intake, or smoking among the impulsive and non-impulsive group of pathological gamblers (Table 5). Regarding the possible differences between other sociodemographic variables such as marital status or education, and nut intake, there was not enough sample size to be able to compare groups.

It is also recommended to take into account other possible confounding variables like comorbidity with substance use disorders (SUD). Although previous investigations [32] suggest patients with gambling disorder often present a high comorbidity with alcohol or substance abuse/dependence and the most impulsive patients tend to be those with higher dual pathology, in this study no association was found between impulsivity and comorbidity with alcohol or other substance use disorders. However, this could be because our participants were recruited from among treatment seekers and they may differ from the general population of pathological gamblers in certain ways. It is also important to consider that individuals with severe SUD (in which an association with impulsivity could be more easily established), are likely to go to specializing units in such addictive disorders rather than

Table 4 Categorization of subjects based on BIS-11

\begin{tabular}{lll}
\hline Categorization BIS-11 & $\mathrm{n}$ & $\%$ \\
\hline Low impulsivity $(<=51)$ & 1 & 1.9 \\
Normal impulsivity $(52-71)$ & 29 & 52.8 \\
High impulsivity $(>=72)$ & 24 & 45.3 \\
Total & 54 & 100 \\
\hline
\end{tabular}

Table 5 Age and other variables in subjects with gambling disorder moderated by the Barratt impulsivity scale

\begin{tabular}{|c|c|c|c|c|}
\hline \multirow{2}{*}{$\begin{array}{l}\text { Variables } \\
\mathrm{m}(\mathrm{SD})^{\mathrm{a}} \\
/ \mathrm{n}(\%)^{\mathrm{b}}\end{array}$} & \multicolumn{2}{|l|}{ BIS-11 } & \multicolumn{2}{|l|}{ Comparison } \\
\hline & $<72(n=29)$ & $\geqq 72(n=24)$ & Test & $p$-values \\
\hline$\overline{\mathrm{Age}^{\mathrm{a}}}$ & 41.1 (13.6) & $41.3(9.9)$ & U Mann Whitney & 0.707 \\
\hline$B M I^{\mathrm{a}}$ & $28.3(5.08)$ & $29.5(3.7)$ & U Mann Whitney & 0.285 \\
\hline Smoker ${ }^{\mathrm{b}}$ & $18(62.10)$ & $18(75)$ & $x^{2}$ & 0.315 \\
\hline Fish $^{b}$ & $12(41.4)$ & $12(52.2)$ & $x^{2}$ & 0.654 \\
\hline
\end{tabular}

gambling, even if they have a comorbid diagnosis of pathological gambling. In fact, these results are extrapolated to the findings of some previous studies such as Ledgerwood et al. (2009) [33], in which no differences in impulsivity measured by the BIS-11 were found between a group of gamblers with and without comorbidity with SUD.

\section{Erythrocyte membrane PUFA composition}

As a quantitative variable, lower value of the AA/EPA ratio was associated with higher scores on the BIS-11 (Table 6).

Analyzing the possible association between the composition of PUFA in the red blood cell membrane and scores in the three subscales of BIS-11, the percentage composition of AA/DHA ratio in red blood cells and scores on non-planning impulsivity subscale was found a negative correlation $(-0.283, p<0.05)$.

It was found statistically significant differences composition of PUFA in the red blood cell between groups. Thus, high impulsive gamblers showed a higher percentage composition of EPA and a lower value of AA/EPA

Table 6 Correlation between PUFA composition in erythrocyte membrane and total scores on the Barratt impulsivity scale. (Omega 3: EPA, DHA, ALA and Omega 6: AA, LA)

\begin{tabular}{lllll}
\hline PUFA (\% erythrocyte membrane) & \multicolumn{3}{l}{ Rho de Spearman } \\
\cline { 3 - 5 } & & $\mathrm{n}$ & Correlation & $p$-values \\
\hline BIS-11 Total & Omega 3 & 50 & 0.180 & 0.211 \\
& Omega 6 & 50 & -0.014 & 0.923 \\
EPA & 50 & 0.264 & 0.064 \\
DHA & 50 & 0.168 & 0.243 \\
ALA & 50 & 0.254 & 0.075 \\
AA & 50 & -0.116 & 0.423 \\
LA & 50 & 0.224 & 0.118 \\
Omega6/Omega3 & 50 & -0.204 & 0.155 \\
AA/EPA & 50 & -0.281 & $0.048^{*}$ \\
AA/DHA & 50 & -0.267 & 0.061 \\
\hline
\end{tabular}

Abbreviations: BIS-11 Barratt Impulsiveness Scale version 11, PUFA polyunsaturated fatty acids, EPA eicosapentaenoic acid, DHA docosahexaenoic acid, $A L A$ alpha-linolenic acid, $A A$ arachidonic acid, $L A$ linoleic acid *Statistical significance $p<0.05$ 
and AA/DHA ratio in erythrocyte membrane than low impulsivity gamblers (Table 7).

\section{Plasma PUFA composition}

It was not found a relationship between the composition of essential fatty acids in plasma and scores on BIS-11 (total and three subscales).

\section{Plasma PUFA concentrations}

There was no statistically significant correlation between plasma PUFA concentrations and total scores on the BIS-11 (as a quantitative variable). Analyzing each of the subscales, just a weak and negative correlation between ALA (alpha-linolenic acid) and scores on the attentional impulsivity subscale was found (Table 8).

Finally, no statistically significant differences in plasma PUFA concentrations were found between impulsive and non-impulsive gamblers (BIS-11 as a qualitative variable).

\section{Discussion}

The main objective of this study is to analyze the association between plasma PUFA concentration or percentage of PUFA in plasma and erythrocyte membrane, and the impulsivity assessed by the BIS-11 in gambling disorder.

In general, the literature suggests a possible weak and negative correlation between omega-3 levels and the impulsivity assessed by BIS-11 [18-20]. However, it must take into account a variety of methodological limitations (small sample size, cross-sectional studies, lifestyle and diet assessment and concomitant medication intake) [12] and there are also no publications comparing PUFA composition between different categories performed based on total scores on the BIS-11. In summary, publications in this field are very scarce and show no enlightening outcomes. To date, there are no published papers that study PUFA in a sample of pathological gamblers.

The present study agrees partially with previous researches, where no correlation was found between plasma EPA and DHA concentration or composition and BIS-11 scores [18]. Although it should be noted that in Conklin et al. (2007), performed in a nonclinical sample, there was a significant statistically significant weak and negative correlation between plasma concentrations $(r=-0.20)$ and plasma percentage composition $(r=-0.26)$ of alpha-linolenic acid (ALA) and total scores on BIS-11. In another study performed in subjects with depression with and without comorbidity with substances uses disorder and controls, only a negative correlation was observed between plasma EPA (not DHA) and total BIS-11 scores in the group with depression and comorbidity with substance use disorder [19]. Finally, it should be mentioned that in another research that aimed to evaluate the difference between plasma concentration of a control group and a group of subjects with self-harm, there was a statistically significant $(p<0.05)$ weak and negative correlation between plasma omega-3 concentrations $(r=-0.23)$ and omega- 6 concentrations $(r=$ - 0.3) and the total scores on the BIS-11 [12].

In contrast, this research found a weak and negative correlation $(r=-0.281, p<0.05)$ between the AA/EPA ratio in the red blood cell membrane and the total scores on BIS-11. It was also observed that the impulsivity group showed a higher percentage composition of EPA

Table 7 PUFA in subjects with gambling disorder moderated by the Barratt impulsivity scale. (Omega 3: EPA, DHA, ALA and Omega 6: $A A, L A)$

\begin{tabular}{|c|c|c|c|c|}
\hline \multirow[t]{2}{*}{$\begin{array}{l}\text { PUFA } \\
\text { (\% erythrocyte membrane) }\end{array}$} & \multicolumn{2}{|l|}{$\begin{array}{l}\text { BIS-11 } \\
\mathrm{m}(\mathrm{SD})\end{array}$} & \multicolumn{2}{|l|}{ Comparison } \\
\hline & $\begin{array}{l}<72 \\
n=29\end{array}$ & $\begin{array}{l}\geqq 72 \\
n=24\end{array}$ & Test & $p$-values \\
\hline Omega 3 & $4.69(0.88)$ & $5.42(1.46)$ & U Mann Whitney & 0.090 \\
\hline Omega 6 & $28.66(2.18)$ & $28,62(2.72)$ & U Mann Whitney & 0.856 \\
\hline EPA & $0.22(0.09)$ & $0.33(0.22)$ & U Mann Whitney & $0.022^{*}$ \\
\hline DHA & $3.37(0.75)$ & $3.91(1.09)$ & U Mann Whitney & 0.075 \\
\hline ALA & $0.03(0.01)$ & $0.04(0.03)$ & U Mann Whitney & 0.056 \\
\hline AA & $14.86(1.82)$ & $14.13(2.37)$ & U Mann Whitney & 0.284 \\
\hline LA & $9.01(1.01)$ & $10.05(2.15)$ & U Mann Whitney & 0.051 \\
\hline Omega6 / Omega3 & $6.35(1.45)$ & $5.64(1.61)$ & U Mann Whitney & 0.082 \\
\hline AA/EPA & $79.13(34.75)$ & $55.99(29.92)$ & U Mann Whitney & $0.015^{*}$ \\
\hline AA/DHA & $4.74(1.94)$ & $3.87(1.24)$ & U Mann Whitney & $0.015^{*}$ \\
\hline
\end{tabular}

Abbreviations: BIS-11 Barratt Impulsiveness Scale version 11, PUFA polyunsaturated fatty acids, EPA eicosapentaenoic acid, DHA docosahexaenoic acid, ALA alphalinolenic acid, $A A$ arachidonic acid, $L A$ linoleic acid

*Statistical significance $p<0.05$ 
Table 8 Correlation between plasma concentrations of PUFA and scores on the Barratt cognitive impulsivity subscale. (Omega 3: EPA, DHA, ALA and Omega 6: AA, LA)

\begin{tabular}{|c|c|c|c|c|}
\hline \multirow[t]{2}{*}{ PUFA (plasma concentration) } & & \multicolumn{3}{|c|}{ Rho Spearman } \\
\hline & & $n$ & Correlation & $p$-values \\
\hline \multirow[t]{10}{*}{ BIS-11 Cognitive Impulsivity } & Omega3 & 52 & -0.158 & 0.264 \\
\hline & Omega6 & 52 & -0.105 & 0.461 \\
\hline & EPA & 52 & -0.076 & 0.594 \\
\hline & DHA & 52 & -0.172 & 0.224 \\
\hline & ALA & 52 & -0.281 & $0.044^{*}$ \\
\hline & $\mathrm{AA}$ & 52 & 0.059 & 0.680 \\
\hline & LA & 52 & -0.181 & 0.198 \\
\hline & Omega6/Omega3 & 52 & 0.046 & 0.747 \\
\hline & AA/EPA & 52 & 0.105 & 0.458 \\
\hline & $\mathrm{AA} / \mathrm{DHA}$ & 52 & 0.214 & 0.128 \\
\hline
\end{tabular}

Abbreviations: BIS-11 Barratt Impulsiveness Scale version 11, PUFA polyunsaturated fatty acids, EPA eicosapentaenoic acid, DHA docosahexaenoic acid, ALA alphalinolenic acid, $A A$ arachidonic acid, $L A$ linoleic acid

*Statistical significance $p<0.05$

and a lower value of AA/EPA and AA/DHA ratio in erythrocyte membrane than the non-impulsivity group. These findings support the hypothesis that alteration of basal PUFA composition exists in disorders characterized by high impulsivity, although the direction of this is still unknown. Unfortunately, the empirical literature on this field is non-existent at the time and we have no direct means to support or refute these outcomes.

Analyzing the association between PUFA and the scores on the three subscales of BIS-11, the current research found a weak and negative correlation $(r=-$ $0.281, p<0.05)$, between plasma concentrations of alpha-linolenic acid (ALA) and scores on the attentional impulsivity subscale. This data is interesting and is in line with literature that supports a possible association between decreased levels of omega-3 and higher impulsivity. However, in the Conklin study (2007), this correlation could not be demonstrated, whereas a weak and negative correlation $(r=-0.2)$ was observed between ALA plasma concentrations $(p<0.05)$ and motor impulsivity subscale scores $(r=-0.2)$, and between plasma concentrations of EPA and DHA and scores on the attentional impulsivity subscale $(r=-0.2)$ [18].

To explain these confusing outcomes, we may need to consider that red blood cell PUFA composition could not reflect the central nervous system PUFA composition. Indeed, some studies have found that plasma omega-3 levels decrease was proportional to the decrease ALA intakes, however, the omega-3 brain concentration, strikingly remained stable despite dietary restrictions or supplements [34]. In addition, PUFAs do not have the same capacity to cross the hematoencephalic barrier and they use different mechanisms to cross it, so it seems wrong to extrapolate the results of what happens in erythrocyte membrane and plasma to the central nervous system [35].

Similarly, it is important to point out that a large volume of the empirical evidence supports an antagonistic action of omega-3 (DHA and EPA) on the signaling of the eicosanoid system dependent on AA metabolism, through several mechanisms [12]. A review of the literature shows that omega-3 and specifically EPA may also have an activating effect on the AA cascade. Although the biochemical mechanisms involved in this process remain unknown, it could be related to the modulation of the activity or expression of the enzymes involved in the release (phospholipase A2) and reuptake (acyltransferase lysophospholipid and CoA fatty acids ligase) of AA in cell membrane phospholipids [12]. This would lead to an increase in AA available for the synthesis of eicosanoids, involved in the modulation and activity of dopaminergic and serotonergic neurotransmission pathways $[36,37]$, which could eventually lead to the appearance of certain symptomatology.

These mechanisms could explain and give coherence to the finding of higher percentage composition of EPA in the erythrocyte membrane in the impulsive group, due to this higher proportion of EPA could result in damage to brain functioning.

However, it should be mentioned that it is complex to determine whether neurobiological variations precede or follow the development of mental disorders, and in this case, as a cross-sectional study, a causal relationship cannot be established. Although in this sample, no significant correlation between PUFA levels and intake of seafood or nuts has been observed, and previous studies say that plasma levels of omega-3 correlate only modestly with omega-3 intake from dietary assessments [38], 
we cannot depreciated completely the role of the dietary in these results or the biological variation between individuals (e.g. differences in absorption and metabolism). Also, point out that the outcomes may be affected by the pharmacological treatment of patients.

The main limitations of the present study are the lack of control group and the small sample size. The generalizability of the current findings is limited by the sample size, demographic and clinical features of the selected sample.

Therefore, future researches should include control group and larger and more generalizable samples. In addition, it would be interesting to have other impulsivity measures, including neuropsychological tests and behavioral tasks, since the multidimensionality and different facets of impulsivity may not be well assessed through BIS-11. Moreover, the use of a validated and standardized outcome measures of impulsivity and PUFA should be implemented when conducting research in this field.

\section{Conclusions}

The results obtained support the hypothesis of a different composition of PUFA among pathological gamblers depending on its impulsivity, showing a higher percentage composition of EPA and a lower AA/EPA ratio and AA/DHA ratio in red blood cell membrane impulsive gamblers. However, as suggested by a part of the literature, these results could go contrary to expectations. These unexpected findings indicate a need for additional investigations to understand the role of EFA in brain functioning, which is even more complex than we can know today.

Therefore, available evidence does not permit us to conclude that a causal relationship exists between n- 6 or n-3 PUFA status and impulsivity in pathological gambling, but it provides a rationale for further exploration of links between disorders characterized by high impulsivity and basal PUFA, as well as for interventional trials.

Work in this field could lead to the use of treatments that are both well tolerated and inexpensive. In all, it is important to discover whether there is a target subgroup of more impulsive gamblers that would preferentially benefit from a supplementation.

\section{Abbreviations \\ AA: Arachidonic acid; ADHD: Attention deficit hyperactivity disorder; ALA: Alpha-linolenic acid; BIS-11: Barratt Impulsiveness Scale version 11; DHA: Docosahexaenoic acid; DSM-IV: Diagnostic and Statistical Manual of Mental Disorders; EFA: Essential fatty acids; EPA: Eicosapentaenoic acid; LA: Linoleic acid; PUFA: Polyunsaturated fatty acids}

\section{Acknowledgments}

Not applicable.

\section{Authors' contributions}

PSP and JPT were responsible for the data collection. OP was responsible for PUFA analysis. PSP and JPT were responsible for all the statistical analysis. Al and JSR conceived the idea for the study and its coordination. PSP wrote the first draft of the paper. JPT revised it critically. PSP, JPT, AI, JSR, and OP all reviewed and edited the manuscript. All authors approved the final version of the manuscript.

\section{Funding}

The authors have received funding from the Spanish Ministry of Economy and Competitiveness (Instituto de Salud Carlos III- Fondo Europeo de Desarrollo Regional -FEDER-; Ref. PI16/00834) and the Centre for Biomedical Research in the Mental Health Network (CIBERSAM).

These sources of funding did not have any role in the design of the study and collection, analysis, and interpretation of data and in writing the manuscript.

\section{Availability of data and materials}

The datasets used and/or analyzed during the current study are available from the corresponding author on reasonable request.

\section{Ethics approval and consent to participate}

The research project was approved by the Comité de Ética de la Investigación (CEIC) del Hospital Universitario Ramón y Cajal. All subjects give voluntary written informed consent to participate in research.

\section{Consent for publication}

Not applicable.

\section{Competing interests}

The authors declare that they have no competing interests.

\section{Author details}

${ }^{1}$ Department of Psychiatry, Hospital Universitario Ramon y Cajal, Madrid, Spain. ${ }^{2}$ Universidad de Alcala, Madrid, Spain. ${ }^{3}$ Instituto Ramon y Cajal de Investigacion Sanitaria (IRyCIS), Madrid, Spain. ${ }^{4}$ Centro de Investigacion Biomedica en Red de SaludMental (CIBERSAM), Madrid, Spain. ${ }^{5}$ Department of Biochemistry, Hospital Universitario Ramon y Cajal, Madrid, Spain. ${ }^{6}$ Centro de Investigacion Biomedica en Red de Fisiopatologia de la Obesidad y la Nutricion (CIBERObn), Madrid, Spain.

Received: 24 April 2019 Accepted: 14 February 2020

Published online: 06 March 2020

\section{References}

1. Evans SJ, Prossin AR, Harrington GJ, Kamali M, Ellingrod VL, Burant CF, et al. Fats and factors: lipid profiles associated with personality factors and suicidal history in bipolar subjects. PLoS One. 2012;7(1):e29297.

2. Burdge GC, Calder PC. Conversion of alpha-linolenic acid to longer-chain polyunsaturated fatty acids in human adults. Reprod Nutr Dev. 2005:45(5): 581-97.

3. Leaf A. The electrophysiologic basis for the antiarrhythmic and anticonvulsant effects of n-3 polyunsaturated fatty acids: heart and brain. Lipids. 2001;36(Suppl):S107-10.

4. Peet $M$, Stokes $C$. Omega-3 fatty acids in the treatment of psychiatric disorders. Drugs. 2005;65(8):1051-9.

5. Calder PC. Mechanisms of action of (n-3) fatty acids. J Nutr. 2012;142(3): 592S-9S.

6. Li D, Hu X. Fish and its multiple human health effects in times of threat to sustainability and affordability: are there alternatives? Asia Pac J Clin Nutr. 2009;18(4):553-63.

7. Gómez Candela C, Bermejo López LM, Loria KV. Importance of a balanced omega 6/omega 3 ratio for the maintenance of health: nutritional recommendations. Nutr Hosp. 2011;26(2):323-9.

8. Gomez-Pinilla F, Tyagi E. Diet and cognition: interplay between cell metabolism and neuronal plasticity. Curr Opin Clin Nutr Metab Care. 2013; 16(6):726-33.

9. Ross BM, Seguin J, Sieswerda LE. Omega-3 fatty acids as treatments for mental illness: which disorder and which fatty acid? Lipids Health Dis. 2007;6:21

10. Thesing CS, Bot M, Milaneschi Y, Giltay EJ, Penninx BWJH. The association of omega-3 fatty acid levels with personality and cognitive reactivity. J Psychosom Res. 2018;108:93-101 Elsevier. 
11. Bègue L, Zaalberg A, Shankland R, Duke A, Jacquet J, Kaliman P, et al. Omega-3 supplements reduce self-reported physical aggression in healthy adults. Psychiatry Res. 2018;261:307-11.

12. Hawkey E, Nigg JT. Omega-3 fatty acid and ADHD: blood level analysis and meta-analytic extension of supplementation trials. Clin Psychol Rev. 2014; 34(6):496-505.

13. Bloch MH, Qawasmi A. Omega-3 fatty acid supplementation for the treatment of children with attention-deficit/hyperactivity disorder symptomatology: systematic review and meta-analysis. J Am Acad Child Adolesc Psychiatry. 2011;50(10):991-1000.

14. Sonuga-Barke EJS, Brandeis D, Cortese S, Daley D, Ferrin M, Holtmann M et al. Nonpharmacological interventions for ADHD: systematic review and meta-analyses of randomized controlled trials of dietary and psychological treatments. Am J Psychiatry. 2013;170(3):275-89.

15. Stevenson J, Buitelaar J, Cortese S, Ferrin M, Konofal E, Lecendreux M, et al. Research review: the role of diet in the treatment of attention-deficit/ hyperactivity disorder--an appraisal of the evidence on efficacy and recommendations on the design of future studies. J Child Psychol Psychiatry. 2014;55(5):416-27.

16. Zaalberg A, Wielders J, Bulten E, van der Staak C, Wouters A, Nijman H. Relationships of diet-related blood parameters and blood lead levels with psychopathology and aggression in forensic psychiatric inpatients. Crim Behav Ment Health. 2016;26(3):196-211.

17. Buydens-Branchey L, Branchey M, McMakin DL, Hibbeln JR. Polyunsaturated fatty acid status and relapse vulnerability in cocaine addicts. Psychiatry Res. 2003;120(1):29-35.

18. Conklin SM, Harris Jl, Manuck SB, Yao JK, Hibbeln JR, Muldoon MF. Serum omega-3 fatty acids are associated with variation in mood, personality and behavior in hypercholesterolemic community volunteers. Psychiatry Res. 2007;152(1):1-10.

19. Beier AM, Lauritzen L, Galfalvy HC, Cooper TB, Oquendo MA, Grunebaum MF, et al. Low plasma eicosapentaenoic acid levels are associated with elevated trait aggression and impulsivity in major depressive disorder with a history of comorbid substance use disorder. J Psychiatr Res. 2014;57(1):133-40.

20. Garland MR, Hallahan B, McNAMARA M, Carney P. A., Grimes H, Hibbeln JR, et al. lipids and essential fatty acids in patients presenting with self-harm. $\mathrm{Br}$ J Psychiatry. 2007;190(2):112-7.

21. Bellino S, Bozzatello P, Rocca G, Bogetto F. Efficacy of omega-3 fatty acids in the treatment of borderline personality disorder: a study of the association with valproic acid. J Psychopharmacol. 2014;28(2):125-32.

22. Hamazaki K, Syafruddin D, Tunru IS, Azwir MF, Asih PB, Sawazaki S, et al. The effects of docosahexaenoic acid-rich fish oil on behavior, school attendance rate and malaria infection in school children--a double-blind, randomized, placebo-controlled trial in Lampung, Indonesia. Asia Pac J Clin Nutr. 2008; 17(2):258-63.

23. First MB, Spitzer RL, Gibbon M, Williams J. Structured clinical interview for DSM-IV-TR Axis I disorders, research version patient edition. (SCID-I/P). New York: Biometrics Research, New York State Psychiatric Institute; 2002

24. American Psychiatric Association. Diagnostic and statistical manual of mental disorders: DSM IV. Washington, DC: American Psychiatric Association; 1994.

25. Jiménez-Murcia S, Stinchfield R, Alvarez-Moya E, Jaurrieta N, Bueno B, Granero R, et al. Reliability, validity, and classification accuracy of a Spanish translation of a measure of DSM-IV diagnostic criteria for pathological gambling. J Gambl Stud. 2009;25(1):93-104.

26. Patton $\mathrm{JH}$, Stanford MS, Barratt ES. Factor structure of the Barratt impulsiveness scale. J Clin Psychol. 1995;51(6):768-74.

27. Stanford M, Mathias C, Dougherty D, Lake S, Anderson N, Patton J. Fifty years of the Barratt impulsiveness scale: an update and review. Personal Individ Differ. 2009;47(5):385-95.

28. Oquendo M, Baca-Garcia E, Graver R, Morales M, Montalvan V, Mann J. Spanish adaptation of the Barratt impulsiveness scale (BIS-11). Eur Psychiatry. 2001;15(3):147-55

29. Tárrega S, Castro-Carreras L, Fernández-Aranda F, Granero R, GinerBartolomé C, Aymamí N, et al. A serious videogame as an additional therapy tool for training emotional regulation and impulsivity control in severe gambling disorder. Front Psychol. 2015;6:1721.

30. Lepage $\mathrm{G}$, Roy $\mathrm{C}$. Direct transesterification of all classes of lipids in a onestep reaction. J Lipid Res. 1986;27(1):114-20.

31. Leppink EW, Grant JE. Traumatic event exposure and gambling: associations with clinical, neurocognitive, and personality variables. Ann Clin Psychiatry. 2015;27(1):16-24.
32. Hodgins DC, Holub A. Components of impulsivity in gambling disorder. Int J Ment Heal Addict. 2015;13(6):699-711.

33. Ledgerwood DM, Alessi SM, Phoenix N, Petry NM. Behavioral assessment of impulsivity in pathological gamblers with and without substance use disorder histories versus healthy controls. Drug Alcohol Depend. 2009; 105(1-2):89-96.

34. Rapoport S, Ramadan E, Basselin M. Docosahexaenoic acid (DHA) incorporation into the brain from plasma, as an in vivo biomarker of brain DHA metabolism and neurotransmission. Prostaglandins Other Lipid Mediat. 2011;96(1-4):109-13.

35. Kuratko C, Salem N. Biomarkers of DHA status. Prostagladin Leukot Essent Fat Acids. 2009;81:111-8

36. Vial D, Piomelli D. Dopamine D2 receptors potentiate arachidonate release via activation of cytosolic, arachidonate-specific phospholipase A2. J Neurochem. 1995:64(6):2765-72.

37. Berg KA, Maayani S, Goldfarb J, Scaramellini C, Leff P, Clarke WP. Effector pathway-dependent relative efficacy at serotonin type $2 \mathrm{~A}$ and $2 \mathrm{C}$ receptors: evidence for agonist-directed trafficking of receptor stimulus. Mol Pharmacol. 1998;54:94-104.

38. Hjartaker A, Lund E, Bjerve KS. Serum phospholipid fatty acid composition and habitual intake of marine foods registered by a semi-quantitative food frequency questionnaire. Eur J Clin Nutr. 1997;51(11):736-42.

\section{Publisher's Note}

Springer Nature remains neutral with regard to jurisdictional claims in published maps and institutional affiliations.
Ready to submit your research? Choose BMC and benefit from:

- fast, convenient online submission

- thorough peer review by experienced researchers in your field

- rapid publication on acceptance

- support for research data, including large and complex data types

- gold Open Access which fosters wider collaboration and increased citations

- maximum visibility for your research: over $100 \mathrm{M}$ website views per year

At $\mathrm{BMC}$, research is always in progress.

Learn more biomedcentral.com/submissions 